\title{
Recycling of Cooking Oil Waste into Reactive Polyurethane for Blending with Thermoplastic Polyethylene
}

\author{
Anika Zafiah M. Rus, ${ }^{1}$ N. Syamimi M. Salim, ${ }^{1}$ and N. Haiza Sapiee ${ }^{1,2}$ \\ ${ }^{1}$ Sustainable Polymer Engineering, Advanced Manufacturing and Material Center (AMMC), Universiti Tun Hussein Onn Malaysia, \\ Batu Pahat, 86400 Parit Raja, Johor, Malaysia \\ ${ }^{2}$ The University of Auckland (UoA), Auckland CBD 1010, New Zealand
}

Correspondence should be addressed to Anika Zafiah M. Rus; zafiah@uthm.edu.my

Received 5 April 2015; Revised 25 June 2015; Accepted 2 August 2015

Academic Editor: Pratheep K. Annamalai

\begin{abstract}
Copyright ( $\odot 2015$ Anika Zafiah M. Rus et al. This is an open access article distributed under the Creative Commons Attribution License, which permits unrestricted use, distribution, and reproduction in any medium, provided the original work is properly cited.
\end{abstract}

\begin{abstract}
Driven by the need of growing to a more sustainable and environmentally friendly future, this research is started by mixing in-house produced biorenewable polymers (BP) from waste cooking oil with the standard low density polyethylene (LDPE) and high density polyethylene (HDPE) via melt-mixing at low ratios. These mixtures are then compounded via injection molding to produce tensile samples. By using the quality of individual compounds injected, the parameters obtained for all ratios of LDPE/BP were the same with neat LDPE whereas some adjustments were required for the HDPE/BP compounds. The corresponding mechanical behaviors of each ratio were also examined and the results showed that both tensile strength and strain of the LDPE/BP were better than neat LDPE. On the other hand, increasing the BP content in HDPE/BP will increase the toughness of the compound if compared to neat HDPE. Therefore, not only does the presence of BP provide renewable properties, but it also improves the mechanical properties. Moreover, the processing temperature and composition of BP will both influence the quality and mechanical behavior of the product made. Thus, this study may aid any intention on processing these in-house produced polymers by injection molding.
\end{abstract}

\section{Introduction}

Polymers in the form of plastics are the most abundant products that we use in our daily life. Nowadays, a majority of the consuming industries use polymers that are synthesized from petroleum sources, for example, polyethylene thermoplastics. Polyethylene is one of the most popular plastics globally and has the simplest structure of all commercial polymers. Two main types of polyethylene are low density polyethylene (LDPE) and high density polyethylene (HDPE) [1].

LDPE and HDPE are two of the most widely used plastics, especially in making plastic bottles, grocery bags, or containers [2]. These polyethylenes can be obtained from polymerization of ethylene. LDPE is produced via free radical polymerization at extremely high pressures, while HDPE is synthesised via Ziegler-Natta polymerization at atmospheric pressure [3]. LDPE is known for its relatively low density due to minor branching in the molecule. Meanwhile, HDPE is well known for its high strength to density ratio. Traditionally, different branch content polyethylenes are blended in order to improve the toughness or processability [4]. Ethylene comes from a nonrenewable source which is petroleum and does not undergo the process of sustainable degradation [5].

Due to the detrimental effects and dependency towards this limited source, there must be methods to replace or improve these plastics $[6,7]$. Currently, there are extensive researches that are being done to accommodate the world's vision in growing to a more sustainable and environmentally friendly future [8]. This leads to a series of studies in producing biorenewable plastics which includes research being done using waste vegetable oil as an alternative feedstock for sustainable monomer $[6,7]$. With the aim of gradually changing these plastics to renewable plastics, the renewable monomers are mixed with these standard thermoplastic polymers.

Braskem, one of the world's leading bioplastic producers, announced the expansion of its resin portfolio with plans to produce 30 kilotonnes of biobased low density polyethylene 
(LDPE) annually. The product has been available on the market since January 2014. Braskem has been producing high density polyethylene (HDPE) and linear low density polyethylene (LLDPE) made from renewable feedstock on an industrial scale. Biobased polyethylene in all its variations has properties identical to those of traditional polyethylene; however, since it is derived from renewable materials, it has decisive advantages, such as reducing greenhouse gas emissions by sequestering carbon dioxide from the atmosphere [9].

Mixing these environmentally friendly hydroxylated biorenewable monomers and crosslinking agents allows biorenewable polymers (BP) to be produced [6, 7]. Combining the BP with the standard LDPE and HDPE is suggested to improve the photodegradation, which is polymer degradation due to light exposure. Even so, having biorenewable polymers without any means of processing them is a waste. The degradation being either photo or thermal may change in aspect of bond scission, chemical transformation, and formation of new functional groups [10]. Degradation rate of PE, exposed to heat or UV light involving thermo- or photooxidation, depends to a great extent on the nature of material and environment it is exposed to [11].

Injection molding is the most common, easy, and commercial method for processing or manufacturing of plastic parts into various products or even for material testing [1214]. Since injection molding is one of the most widely used methods for processing thermoplastics, this paper aims to determine and understand the processing conditions of the LDPE/SP and HDPE/SP compound by injection molding [13]. An important advantage of injection molding is that complex geometries can be made easily in one production step in an automated process. The injection molding machine operates by first pouring the materials in the hopper which leads to the heated barrel equipped with a reciprocating screw [14]. After the material is heated to a molten state, the screw pushes the content into a mold via the nozzle with sufficient cooling time and the product will be ejected.

Being the most important process in manufacturing plastic product, injection molding produced mass-producing products since raw material can be converted into a solid shape by single procedure. It is undeniable that, for any process, the processing temperatures are one of the key factors which gives most impact on the properties or the processability of the product. Therefore, this research focuses on the parameters, mainly temperature, needed to produce several mixed ratios of these green polymers and LDPE or HDPE by injection molding. The presence of biorenewable polymers in the compound may lower the processing conditions required, which will save energy consumption. Besides that, the resulting mechanical properties of each of the injected samples will also be analysed.

\section{Experimental}

2.1. Raw Materials. The raw materials in this work included low density polyethylene (LDPE) (melt index $=5 \mathrm{~g} / 10 \mathrm{~min}$, density $=0.922 \mathrm{~g} / \mathrm{cm}^{3}$, and Vicat softening point $\left.=93^{\circ} \mathrm{C}\right)$, high density polyethylene (HDPE) (melt index $=4 \mathrm{~g} / 10 \mathrm{~min}$, density $=0.957 \mathrm{~g} / \mathrm{cm}^{3}$, and Vicat softening point $\left.=124^{\circ} \mathrm{C}\right)$, flexible and rigid polymethane polyphenyl isocyanate (modified polymeric MDI) (viscosity at $25^{\circ} \mathrm{C}=120-160 \mathrm{cps}$, specific gravity at $25^{\circ} \mathrm{C}=1.18-1.20 \mathrm{~g} / \mathrm{mL}, \mathrm{NCO}$ content, and $\% \mathrm{wt}=$ 26.3-27.3), and biorenewable monomers (sustainable polyol).

2.2. Synthesis of Biorenewable Polyol. The biorenewable monomer conversions from waste vegetable oils were chemically manipulated at the laboratory scale using less than $1 \mathrm{~L}$ of vegetable oil $[6,7,15]$.

The preparation of the hydroxylated biorenewable monomer was divided into two stages: the first stage is the preparation of catalyst to generate the epoxides from the unsaturated fatty compounds, while the second stage is the acid-catalysed ring-opening of the epoxides to form polyols.

The catalyst preparation was as follows: distilled water $(0.6 \mathrm{~mL})$ and hydrogen peroxide $(1.26 \mathrm{~mL}, 30 \% \mathrm{w} / \mathrm{w})$ were added and the solution was heated at $50^{\circ} \mathrm{C}$ and thoroughly stirred (for about 30 minutes) and cooled to room temperature and concentrated aqueous orthophosphoric acid (90 mg, $85 \% \mathrm{w} / \mathrm{w})(1.2 \mathrm{~mL})$ was poured in.

Waste vegetable oil $(30 \mathrm{gm})$ was heated at $50^{\circ} \mathrm{C}$ and the catalyst prepared earlier was added, followed by water $(50 \mathrm{~mL})$. Orthophosphoric acid (15 gm, 85\% w/w) and hydrogen peroxide $(18 \mathrm{~mL}, 30 \% \mathrm{w} / \mathrm{w})$ were added dropwise to the mixture. The mixture was heated at $90^{\circ} \mathrm{C}$ and stirred for 6 hours. This yielded the hydroxylated biorenewable monomer.

2.3. Preparation of Samples. In general, the hydroxylated biorenewable monomer is reacted with the crosslinking agent, namely, flexible or rigid modified polymeric 4,4dimethylen-bis-(phenylisocyanate) (MDI), to produce biorenewable polymer (BP). BP were prepared by adding the hydroxylated biorenewable monomer ( $1 \mathrm{gm}$; $0.2 \mathrm{gm}$ equivalent weight with polyol) with an appropriate amount of flexible or rigid MDI ( $0.5 \%$ equivalent weight of polyol). The mixture was mechanically stirred until a viscous compound resulted which was left to cure at room temperature for at least 6 hours until the disappearance of $\mathrm{N}=\mathrm{C}=\mathrm{O}$ groups as measured by IR spectroscopy.

Meanwhile, for the compounding process, liquidized BP (as prepared according to previous step but avoiding it to be left and cured at predetermined time) is mixed with LDPE and HDPE by manually stirring until the BP solidifies and adheres on the surface of LDPE or HDPE surfaces. The weights of compositions were determined based on ratio of BP and LDPE and HDPE, respectively. Samples were made with $1 \%$ of BP (wt/wt ratio) to $100 \%$ of LDPE or HDPE. The same method was used to mix $2 \%, 3 \%, 4 \%$, and $5 \%$ of BP with LDPE and HDPE with either flexible or rigid crosslinkers.

The LDPE/BP and HDPE/BP specimens were then fed to the injection molding machine (Nissei Horizontal Screw Type Injection Molding NP7) equipped with a mold of tensile specimens according to ISO 527 (5A). Using the general processing conditions for pure LDPE and HDPE along with the TGA results as a guideline to determine the initial parameters, the quality of the resulting test bars was used as a benchmark to adjust the parameters for changing ratios. 


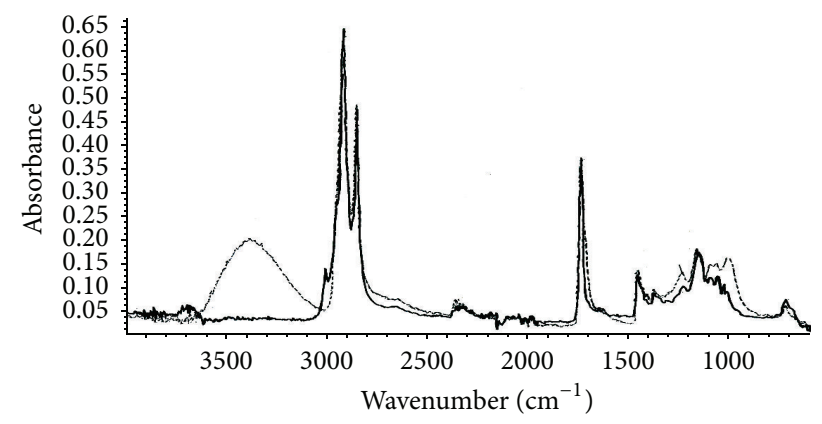

FIGURE 1: IR spectra of waste vegetable oil (bold line) and the corresponding biorenewable polyol (dotted line).

2.4. Spectroscopic and Thermal Characterization. The starting vegetable oils and their hydroxylated monomers, namely, biorenewable monomer, are identified by means of Fourier transform infrared (FTIR) spectroscopy. The thermal gravimetric analysis (TGA) measurement of BP was performed using Linseis TGA to characterize the thermal properties of the BP according to ISO 11358. TGA is an analytical technique that measures the decomposition weight loss of a small polymer sample as a function of time or temperature. It provides a quantitative description of the thermal stability of a material and the amount of the corresponding residue. The weight loss and derivative weight loss were measured at $20^{\circ} \mathrm{C}$ to $900^{\circ} \mathrm{C}$ with heating rate of $10^{\circ} \mathrm{C} / \mathrm{min}$ under oxygen atmosphere and flow rate of $0.3 \mu \mathrm{L}$ using alumina crucible.

2.5. Mechanical Characterization. The Universal Tensile Machine AG-I, Shimadzu, $10 \mathrm{kN}$ with a $5 \mathrm{~mm} / \mathrm{min}$ crosshead speed, was used to analyse the respective mechanical properties of the specimens produced at each parameter [16]. Then tensile tests of five samples from each composition were tested and an average value was obtained. The tensile strength and strain of each specimen were obtained and tabulated to be examined.

2.6. Structural Characterization. In order to perform a fracture analysis on each specimen, the fractures were observed under a scanning electron microscope (SEM). The samples were initially coated with platinum and observed at different magnifications. However, the magnifications at $500 \mathrm{x}$ were carefully observed.

\section{Results and Discussion}

3.1. The Infrared Spectra of the Synthesized Biorenewable Polymer (Polyurethane) and Its Thermal Characterization. The IR spectra (Figure 1) of the biorenewable polyols show an intense, new broad peak at $3400 \mathrm{~cm}^{-1}$ that verifies the presence of hydrogen bonded hydroxyl $(\mathrm{OH})$ groups in the synthesized product. (The $\mathrm{OH}$ group will then react with diisocyanate to form the polyurethane polymer, namely, biorenewable polymer (BP).) Otherwise, the principal IR bands are much in the same location for all four compounds.

The infrared spectra of the synthesized BP of waste vegetable oil-based polyurethane are shown in Figure 2. It is

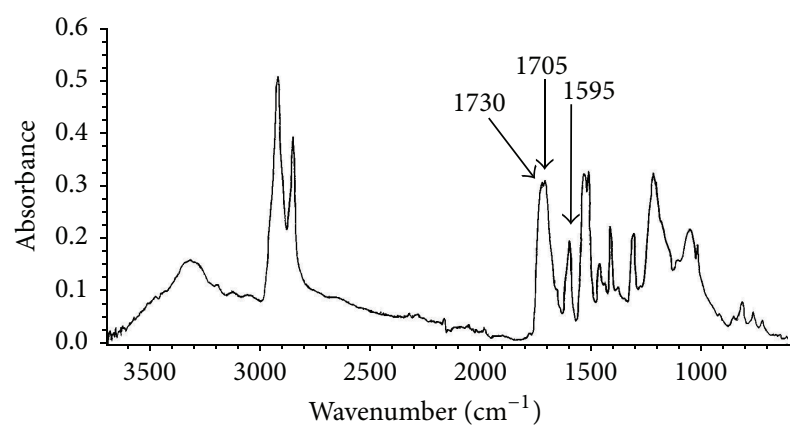

FIGURE 2: FTIR spectrum for biorenewable polymer of waste vegetable oil-based polyurethane.

clearly seen that the polyurethane was fully cured. This is evidenced by the reduction and almost complete disappearance of the NCO peak at $2275 \mathrm{~cm}^{-1}$. The following characteristic bands in the FTIR spectra were observed: $3300,1720,1525$, 1220 , and $1086 \mathrm{~cm}^{-1}$ (this band is attributed to the formation of urethane structures $-\mathrm{NH}[6,7]), 2800-3000 \mathrm{~cm}^{-1}(\mathrm{CH}$ stretching vibrations), $2919 \mathrm{~cm}^{-1}$ (asymmetric $\mathrm{CH}_{2}$ stretching), and $2853 \mathrm{~cm}^{-1}$ (symmetric $\mathrm{CH}_{2}$ stretching).

An absorption peak was observed at the $1595 \mathrm{~cm}^{-1}$ band corresponding to the $\mathrm{C}=\mathrm{C}$ stretching vibration in the aromatic rings of MDI. A strong band, assigned to hydrogen bonded $-(\mathrm{NH}-\mathrm{C}=\mathrm{O}-\mathrm{O})-$ stretching vibrations, is present at $1705 \mathrm{~cm}^{-1}$. A free (non-hydrogen bonded) $\mathrm{C}=\mathrm{O}$ stretch appears as a shoulder on the high-wavenumber side of this band (at $1730 \mathrm{~cm}^{-1}$, Figure 2).

Referring to Figure 3, the weight loss curves (TG), and derivative thermogravimetric (DTG) evaluation of SP samples, the initial temperatures for injection molding were ensured not to exceed the degradation temperature. The first peak appeared at the temperature range less than $100^{\circ} \mathrm{C}$ due to the beginning of weight loss of volatile material [17], moisture drying stage [18], moisture evolution of water [19], and water evaporation $[20,21]$ in the DTG evaluation profile of the samples.

Qualitative characterization of the degradation process is elaborated by the onset and maximum peak temperature of the first step $T_{10 n}$ and $T_{1 \max }$ along with the same for second step $T_{2 \text { on }}$ and $T_{2 \max }$. The detail of TGA onset decomposition temperature $\left(T_{\text {onset }}\right)$ and the maximum decomposition temperature $\left(T_{\max }\right)$ for $\mathrm{BP}$ is shown in Table 1. The onset degradation temperature $T_{\text {onset }}$ and the maximum degradation rate temperature $T_{1 \max }$ of the first $\mathrm{BP}$ degradation stage are $238^{\circ} \mathrm{C}$ and $419^{\circ} \mathrm{C}$, respectively. The first peak of polymer decomposition temperature represents the hard segment, while the second peak represents the degradation of the soft segment. Figure 2 shows the derivative weight loss of BP is more than $93.7 \%$. The weight loss of BP which started at less than $100^{\circ} \mathrm{C}$ indicated that the volatile matter in samples is equivalent to $4.3 \%$.

Meanwhile, the decomposition temperature is attributed to the crosslinker of flexible isocyanate content. It has been suggested that the amount of weight loss at each degradation stage may be used as a quantitative measurement of the hard 
TABLE 1: Thermal property of BP sample.

\begin{tabular}{lc}
\hline Samples & BP \\
\hline First decomposition $\left[{ }^{\circ} \mathrm{C}\right]$ & 238 \\
$T_{\text {on }}\left[{ }^{\circ} \mathrm{C}\right]$ & 94 \\
$T_{\max }\left[{ }^{\circ} \mathrm{C}\right]$ & 283 \\
Weight loss [\%] & $19.5 \%$ \\
Second decomposition $\left[{ }^{\circ} \mathrm{C}\right]$ & 419 \\
$T_{\text {on }}\left[{ }^{\circ} \mathrm{C}\right]$ & 283 \\
$T_{\max }\left[{ }^{\circ} \mathrm{C}\right]$ & 494 \\
Weight loss $[\%]$ & $57.4 \%$ \\
Third decomposition $\left[{ }^{\circ} \mathrm{C}\right]$ & 567 \\
$T_{\text {on }}\left[{ }^{\circ} \mathrm{C}\right]$ & 494 \\
$T_{\max }\left[{ }^{\circ} \mathrm{C}\right]$ & 678 \\
Weight loss $[\%]$ & $16.8 \%$ \\
\hline
\end{tabular}



FIGURE 3: Thermogram (TG) and derivative weight loss (DTG) of BP samples.

and soft content in BP. This is indicated by the first weight loss of BP which is approximately similar to the first decomposition temperature at $238^{\circ} \mathrm{C}$ and second decomposition temperature is at $419^{\circ} \mathrm{C}$, respectively.

3.2. Injection Molding Parameters. Based on the results obtained from the TGA, the injection molding temperatures of each zone were ensured not to exceed $238^{\circ} \mathrm{C}$. This is to make sure that the BP does not decompose before injection. Then, by referring to the melting temperatures and typical injection molding temperatures of both pure LDPE and HDPE, the initial parameters were set. The next several temperature values with increasing $\mathrm{BP}$ composition were adjusted to ensure that the best samples were produced.

For all compositions of the LDPE/BP compound, regardless of the type of crosslinker used, there was no need to adjust the temperature values of feed, rear 1 , rear 2 , middle, front, and nozzle zones. These values are listed in Table 2.

Based on the values tabulated in Table 2, the LDPE/BP compounds were able to be processed at the same parameters as neat LDPE, regardless of the addition of BP. This is beneficial as the processing of these proposed biorenewable plastics will not require any additional cycle time. However,
TABLE 2: The main injection moulding parameters used for LDPE/ SP compounds.

(a)

\begin{tabular}{lcccccc}
\hline $\begin{array}{l}\text { Injection Injection } \\
\text { pressure } \\
\text { rate } \\
{[\mathrm{MPa}]}\end{array}$ & $\begin{array}{c}\text { Holding } \\
{\left[\mathrm{cm}^{3} / \mathrm{s}\right]}\end{array}$ & $\begin{array}{c}\text { pressure } \\
{[\mathrm{MPa}]}\end{array}$ & $\begin{array}{c}\text { Holding } \\
\text { time }[\mathrm{s}]\end{array}$ & $\begin{array}{c}\text { Cooling }[\mathrm{s}] \\
\text { time }\left[\begin{array}{c}\text { Injection } \\
\text { time }[\mathrm{s}]\end{array}\right.\end{array}$ & $\begin{array}{c}\text { Cycle } \\
\text { time } \\
{[\mathrm{s}]}\end{array}$ \\
\hline 43.4 & 15.0 & 43.4 & 2.0 & 10.0 & 2.0 & 22.0 \\
\hline
\end{tabular}

(b)

\begin{tabular}{lccccc}
\hline \multicolumn{5}{c}{ Temperature $\left[{ }^{\circ} \mathrm{C}\right]$} \\
Feed & Rear 1 & Rear 2 & Middle & Front & Nozzle \\
\hline 50.0 & 165.0 & 170.0 & 175.0 & 180.0 & 185.0 \\
\hline
\end{tabular}

if further development of the compound to be processed at lower temperature, lower injection pressure with reduction of cycle time should be considered. Due to lower temperature and injection pressure required for processing, less energy is consumed and thermal degradation of BP is reduced.

Meanwhile, for the HDPE/BP compounds, the parameters, mainly temperature, had to be adjusted to ensure the melt filled the mold entirely. All of the specimens injected were individually examined from any defect. The respective values are tabulated in Table 3.

According to these results, the parameters used for neat HDPE were the same at low percentages of BP with the flexible crosslinkers. However, when the composition of BP was increased, the temperatures had to be increased as silver streaks started to appear. Not only that, pressure also needed to be increased for the melt to completely fill the mold. This definitely opposed the initial idea of lowering processing conditions to save energy consumption.

The increase in values of the parameters may be due to the presence of HDPE. Its high density may have influenced the mixing conditions to increase. Nevertheless, in further research, the processing temperatures will be tried to be reduced and the resulting effects on the mechanical properties will be studied. This may significantly reduce the energy consumption for processing of these compounds. However, the visual observations cannot stand alone; henceforth, the corresponding mechanical properties for each compound were analyzed.

3.3. Mechanical Characterization. The mechanical properties of the compounds were analyzed based on their tensile strength and strain or elongation at break. These data were obtained through the tensile test performed. Table 4 shows the tensile test experimental data for all LDPE/BP compounds developed in this work.

The tensile strength measurement shows a peculiar trend as it significantly increases at low percentages of BP and gradually declines with addition of the BP. The same trend is observed for the elongation at break of the samples. This could be due to the soft properties of the BP blended with the strong properties of the LDPE producing a tough and strong compound. Not only does the presence of BP allow it to be more renewable, but it also improves the mechanical properties. 
TABLE 3: The main injection molding parameters used for HDPE/BP compounds.

\begin{tabular}{|c|c|c|c|c|c|c|}
\hline \multirow{3}{*}{ Parameters } & \multirow{3}{*}{ Neat } & \multicolumn{4}{|c|}{ HDPE } & \multirow[b]{3}{*}{$5 \% \mathrm{BP}$} \\
\hline & & \multicolumn{4}{|c|}{ Flexible crosslinker } & \\
\hline & & $1 \% \mathrm{BP}$ & $2 \% \mathrm{BP}$ & $3 \% \mathrm{BP}$ & $4 \% \mathrm{BP}$ & \\
\hline Injection pressure $[\mathrm{MPa}]$ & 96.6 & 96.6 & 96.6 & 104.7 & 104.7 & 104.7 \\
\hline Injection rate $\left[\mathrm{cm}^{3} / \mathrm{s}\right]$ & 25.0 & 25.0 & 25.0 & 15.0 & 15.0 & 15.0 \\
\hline Holding pressure $[\mathrm{MPa}]$ & 96.6 & 96.6 & 96.6 & 104.7 & 104.7 & 104.7 \\
\hline Holding time $[\mathrm{s}]$ & 2.0 & 2.0 & 2.0 & 2.0 & 2.0 & 2.0 \\
\hline Cooling time $[\mathrm{s}]$ & 10.0 & 10.0 & 10.0 & 10.0 & 10.0 & 10.0 \\
\hline Injection time $[\mathrm{s}]$ & 2.0 & 2.0 & 2.0 & 2.0 & 2.0 & 2.0 \\
\hline Cycle time [s] & 22.0 & 22.0 & 22.0 & 22.0 & 22.0 & 22.0 \\
\hline \multicolumn{7}{|l|}{ Temperature $\left[{ }^{\circ} \mathrm{C}\right]$} \\
\hline Feed & 50.0 & 50.0 & 50.0 & 60.0 & 60.0 & 55.0 \\
\hline Rear 1 & 175.0 & 175.0 & 175.0 & 185.0 & 185.0 & 175.0 \\
\hline Rear 2 & 165.0 & 165.0 & 165.0 & 175.0 & 175.0 & 165.0 \\
\hline Middle & 180.0 & 180.0 & 180.0 & 190.0 & 190.0 & 180.0 \\
\hline Front & 195.0 & 195.0 & 195.0 & 205.0 & 205.0 & 195.0 \\
\hline Nozzle & 205.0 & 205.0 & 205.0 & 215.0 & 215.0 & 205.0 \\
\hline \multirow{3}{*}{ Parameters } & \multicolumn{6}{|c|}{ HDPE } \\
\hline & \multirow{2}{*}{ Neat } & \multicolumn{5}{|c|}{ Rigid crosslinker } \\
\hline & & $1 \% \mathrm{BP}$ & $2 \% \mathrm{BP}$ & $3 \% \mathrm{BP}$ & $4 \% \mathrm{BP}$ & $5 \% \mathrm{BP}$ \\
\hline Injection pressure $[\mathrm{MPa}]$ & 96.6 & 104.7 & 104.7 & 104.7 & 104.7 & 104.7 \\
\hline Injection rate $\left[\mathrm{cm}^{3} / \mathrm{s}\right]$ & 25.0 & 15.0 & 15.0 & 15.0 & 15.0 & 15.0 \\
\hline Holding pressure $[\mathrm{MPa}]$ & 96.6 & 104.7 & 104.7 & 104.7 & 104.7 & 104.7 \\
\hline Holding time $[s]$ & 2.0 & 2.0 & 2.0 & 2.0 & 2.0 & 2.0 \\
\hline Cooling time $[\mathrm{s}]$ & 10.0 & 10.0 & 10.0 & 10.0 & 10.0 & 10.0 \\
\hline Injection time $[\mathrm{s}]$ & 2.0 & 2.0 & 2.0 & 2.0 & 2.0 & 2.0 \\
\hline Cycle time [s] & 22.0 & 22.0 & 22.0 & 22.0 & 22.0 & 22.0 \\
\hline \multicolumn{7}{|l|}{ Temperature $\left[{ }^{\circ} \mathrm{C}\right]$} \\
\hline Feed & 50.0 & 55.0 & 55.0 & 55.0 & 55.0 & 55.0 \\
\hline Rear 1 & 175.0 & 175.0 & 175.0 & 175.0 & 175.0 & 175.0 \\
\hline Rear 2 & 165.0 & 165.0 & 165.0 & 165.0 & 165.0 & 165.0 \\
\hline Middle & 180.0 & 180.0 & 180.0 & 180.0 & 180.0 & 180.0 \\
\hline Front & 195.0 & 195.0 & 195.0 & 195.0 & 195.0 & 195.0 \\
\hline Nozzle & 205.0 & 205.0 & 205.0 & 205.0 & 205.0 & 205.0 \\
\hline
\end{tabular}

TABLE 4: The mechanical properties for the LDPE/BP injected sample.

\begin{tabular}{|c|c|c|c|c|c|c|c|c|c|c|c|}
\hline \multirow{3}{*}{ Parameters } & \multicolumn{11}{|c|}{ LDPE } \\
\hline & \multirow{2}{*}{ Neat } & \multicolumn{5}{|c|}{ Flexible crosslinker } & \multicolumn{5}{|c|}{ Rigid crosslinker } \\
\hline & & $1 \% \mathrm{BP}$ & $2 \% \mathrm{BP}$ & $3 \% \mathrm{BP}$ & $4 \% \mathrm{BP}$ & $5 \% \mathrm{BP}$ & $1 \% \mathrm{BP}$ & $2 \% \mathrm{BP}$ & $3 \% \mathrm{BP}$ & $4 \% \mathrm{BP}$ & $5 \% \mathrm{BP}$ \\
\hline Tensile strength [MPa] & 8.9 & 11.3 & 10.9 & 10.6 & 10.1 & 9.9 & 11.8 & 11.3 & 10.8 & 10.2 & 9.9 \\
\hline Tensile strain [\%] & 67.6 & 71.4 & 70.2 & 69.2 & 68.3 & 67.8 & 79.6 & 74.8 & 72.1 & 71.4 & 66.0 \\
\hline
\end{tabular}

Plasticization effect explains a change in the thermal and mechanical properties of a given polymer by the lowering of rigidity at room temperature. This can clarify the general increment of tensile strain. Polymer chains which possess a regular structure are able to crystallize under suitable conditions, either from the melt or from solution. This indicates that the chain molecules change from a coiled and disordered state to a tightly folded aligned and ordered state. Besides that, there was no significant difference seen between different types of crosslinkers. Further explanation can be provided by the fracture analysis which is done in the next section. On the other hand, Table 5 revealed the mechanical properties of the HDPE/SP compounds.

The HDPE provides ductility that exhibits brittle behaviour with a subsequent loss of toughness to the compounding materials $[22,23]$. The addition of BP generally increases the toughness and decreases the strength of the compound. This could be due to the soft properties of the SP. Tensile strength measurements indicated that the mechanical property values decrease with increasing BP 
TABLE 5: The mechanical properties for the HDPE/BP injected sample.

\begin{tabular}{|c|c|c|c|c|c|c|c|c|c|c|c|}
\hline \multirow{3}{*}{ Parameters } & \multicolumn{11}{|c|}{ HDPE } \\
\hline & \multirow{2}{*}{ Neat } & \multicolumn{5}{|c|}{ Flexible crosslinker } & \multicolumn{5}{|c|}{ Rigid crosslinker } \\
\hline & & $1 \% \mathrm{BP}$ & $2 \% \mathrm{BP}$ & $3 \% \mathrm{BP}$ & $4 \% \mathrm{BP}$ & $5 \% \mathrm{BP}$ & $1 \% \mathrm{BP}$ & $2 \% \mathrm{BP}$ & $3 \% \mathrm{BP}$ & $4 \% \mathrm{BP}$ & $5 \% \mathrm{BP}$ \\
\hline Tensile strength [MPa] & 35.5 & 33.1 & 32.0 & 28.6 & 28.6 & 26.0 & 33.9 & 34.1 & 33.7 & 33.8 & 33.3 \\
\hline Tensile strain [\%] & 37.8 & 37.8 & 44.0 & 47.6 & 47.1 & 53.5 & 44.7 & 43.0 & 39.0 & 36.7 & 36.8 \\
\hline
\end{tabular}

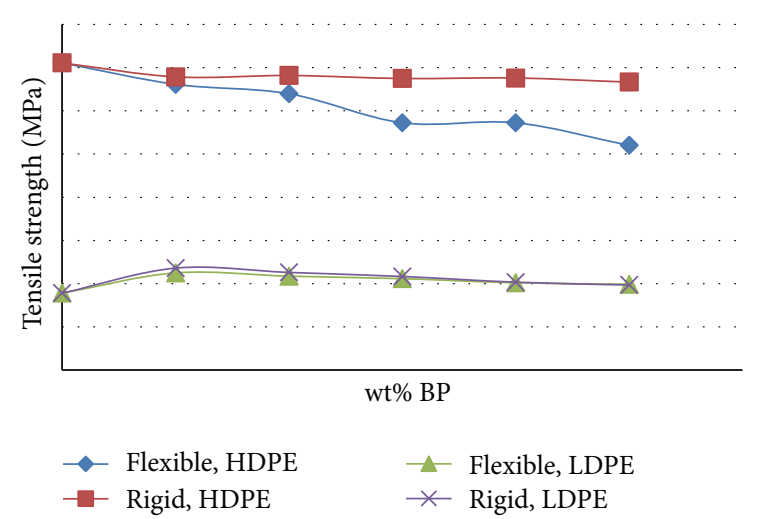

FIGURE 4: Tensile strengths for all specimens injected at respective compositions.

content in the sample which used the flexible crosslinker. However, for the samples with rigid crosslinker, regardless of the BP content, the tensile strength remained approximately stagnant at 33 to $34 \mathrm{MPa}$. This is probably due to traits of the flexible and rigid crosslinkers. Flexible polyurethane is usually used for cushioning and packaging, while rigid polyurethane is used for insulation and packaging. The general declining trend may be due to the soft properties of the BP.

Meanwhile, the elongation at break increased for the sample with flexible crosslinker and vice versa for rigid crosslinker. The higher tensile strain of HDPE/BP compound compared to neat HDPE may also be due to plasticization effect. Based on these results, when the BP is added with flexible isocyanate, it may act as a filler as it improves the tensile strain values.

If both the samples of LDPE/BP and HDPE/BP compounds were to be compared, it can be said that the strength of HDPE/BP is significantly better than that of LDPE/BP. This can be seen in Figure 4.

The significant difference in tensile strength can be explained by the individual properties of HDPE and LDPE. HDPE is well known for its strong properties. Therefore, the same characteristics were observed even after addition of the $\mathrm{BP}$ with crosslinkers.

Besides that, the tensile strain of the LDPE/BP compound is observed to be higher than the HDPE/BP compound. This is shown in Figure 5.

The high value of elongation at break for the LDPE/BP compound is due to the more flexible properties. This allows it to significantly yield before breaking, leading to a high value of tensile strain. Therefore, LDPE/BP is comparatively more flexible than HDPE/BP.

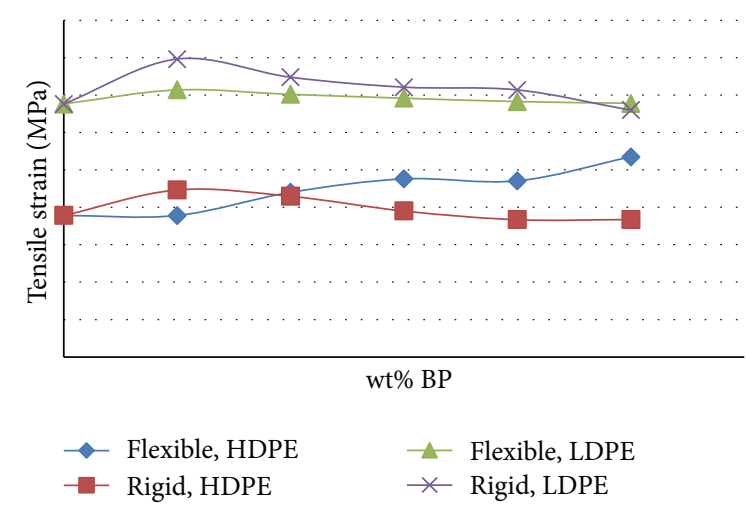

FIGURE 5: Tensile strains for all specimens injected at respective compositions.

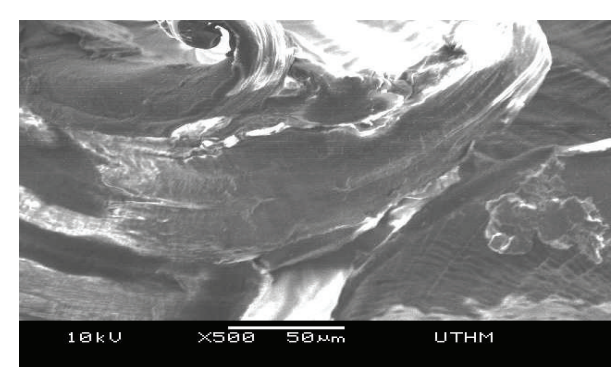

FIGURE 6: SEM image of fractured neat LDPE at 500x magnification.

Both these results are favorable as they do not alter the properties of the HDPE or LDPE too drastically and hence can allow the compound to gradually replace the usage of both HDPE and LDPE in industries.

3.4. Fracture Analysis. The fracture analysis was performed in order to understand and examine the fracture at a specific magnification. Besides that, it can also demonstrate the homogeneity of the compound injected. This can be done by placing the sample under a scanning electron microscope (SEM). Various magnifications were observed, but for the purpose of this study the images were taken at 500x magnification.

Figure 6 shows the SEM image obtained for neat LDPE, while Figure 7 shows the SEM images obtained for LDPE/SP compounds after fracture. The images show the general structure of the injected sample.

From Figure 6, it can be seen that the fracture is ductile. This is due to the significant elongation or necking before break. Also the plastic deformation which can be seen by 
LDPE/BP
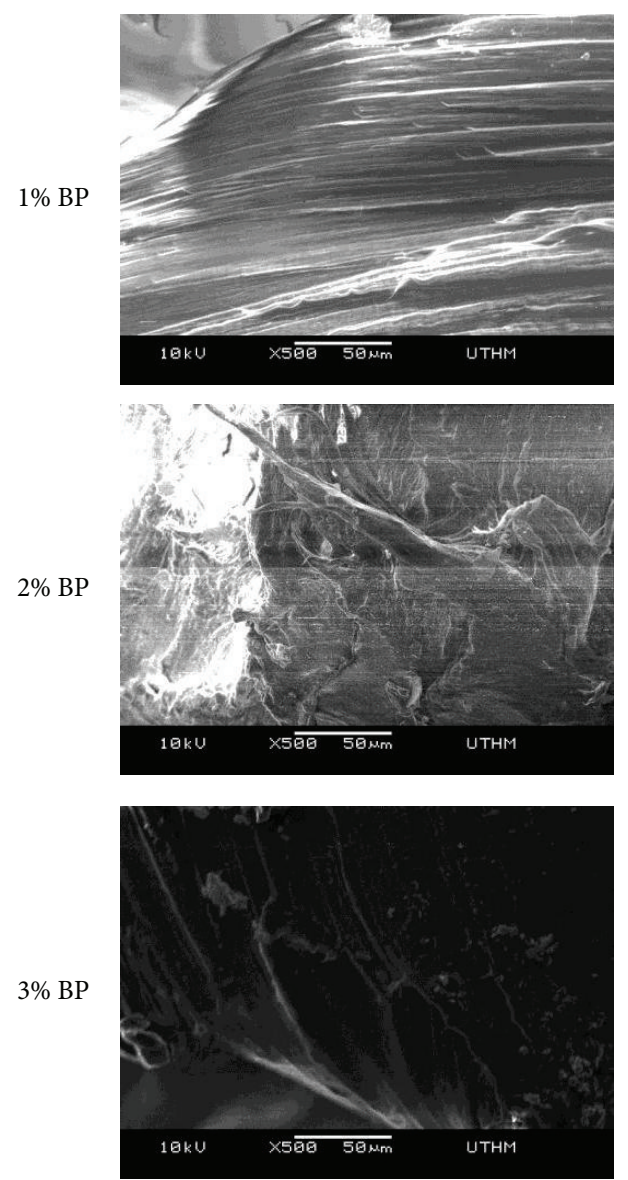

$3 \% \mathrm{BP}$

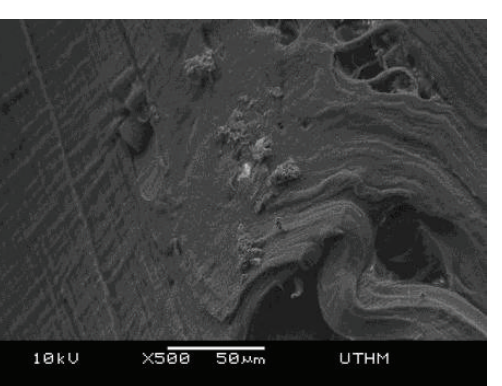

$4 \% \mathrm{BP}$

$5 \% \mathrm{BP}$

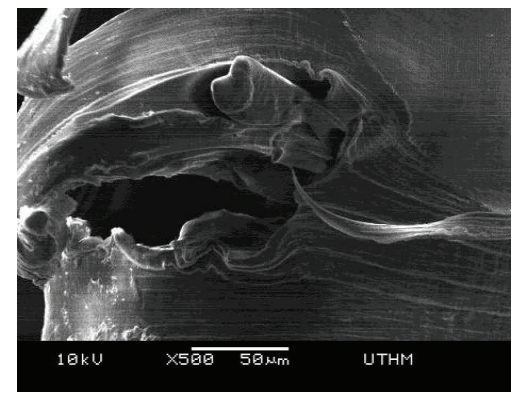

FIgURE 7: SEM images for all LDPE/BP specimens at 500x magnifications.

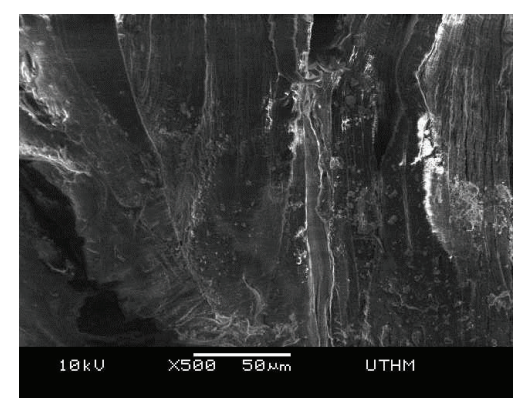

Rigid crosslinker
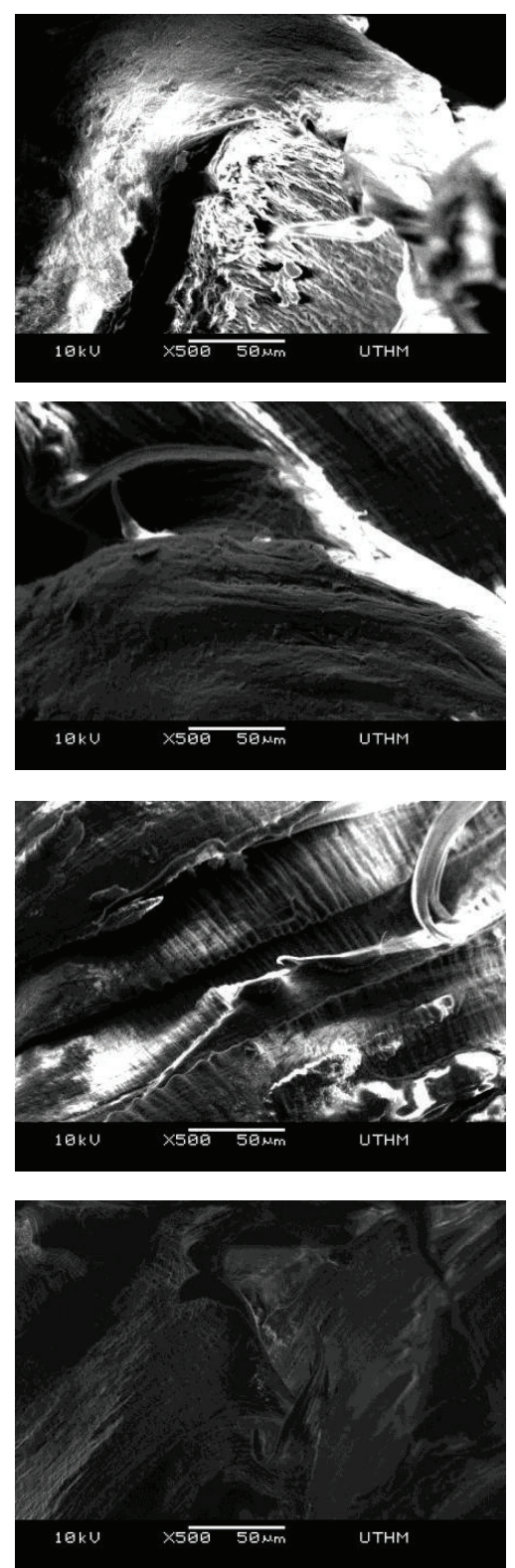


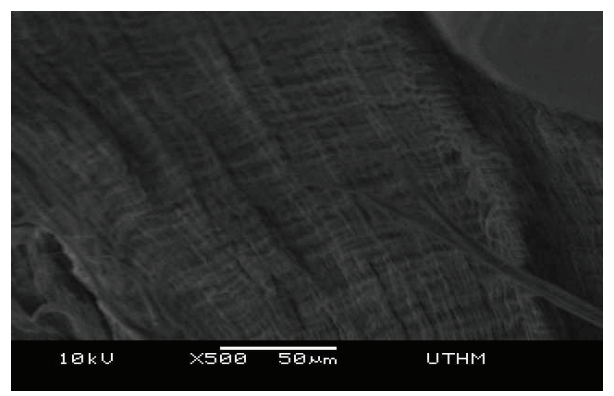

FIGURE 8: SEM image for fractured neat HDPE at 500x magnification.

the tear lines occurring on the fractured surface supported the deduction [24]. However, there might have been some stress points that could be observed due to the partially melted LDPE structure. The oval shaped structure appearing in the SEM of neat LDPE proves that these structures are not due to the BP as examined in Figure 7. Instead, they may be impurities or unmelted LDPE.

Various structures were observed through these images but it can be concluded that the BP content in the compound enables it to significantly elongate before breaking, in addition to the ductile properties of pure LDPE. Due to lower temperature and injection pressure required for processing, less energy is consumed and thermal degradation of BP is reduced. This can be proved via the long strands formed at each fracture. Having this property can allow these compounds to be used in diverse applications which require tough or highly ductile materials.

Besides that, blobs of material which are inhomogeneous to the entire sample are seen in the LDPE/BP compounds linked with flexible crosslinkers. The foamy structure may identify these blobs as the crosslinkers which may have not completely been mixed with the compound. It could also be due to the processing conditions during injection molding.

Since the blobs are not obviously seen in the LDPE/BP compound with the rigid crosslinker, it contributed to better mechanical properties than with the flexible crosslinker. Meanwhile Figure 6 shows the SEM image for neat HDPE and Figure 8 shows the SEM for all HDPE/BP samples.

The tear lines as seen in Figure 8 may represent plastic deformation and again can be proven by the tear lines, as in Figure 9. The image portrays that a homogeneous melt of HDPE was injected. The SEM images for the fractured HDPE/BP compounds are shown in Figure 9.

Based on the images, it can be seen that the structures may not be completely homogeneous as some rough surfaces can be seen. Some strands which demonstrate plastic deformation and a ductile failure can also be observed. If compared to the LDPE/BP images, no foamy structures were seen which may prove that the temperature used in injection molding is approximately accurate.

These findings can help support the fact that not only the composition of BP but also the parameters used in injection molding, mainly temperature, do give an impact on the mechanical properties of the HDPE/BP compound produced.

\section{Conclusion}

By using melt-mixing during the injection molding process, new compounding polymers based on different ratio of BP to LDPE or HDPE were successfully produced. The processing conditions of LDPE/BP and HDPE/BP, renewable plastics, by injection molding were determined and analyzed. The initial processing conditions of the standard LDPE and HDPE thermoplastic were used as a base point. It was concluded that the processing conditions of the LDPE/BP compound, a renewable plastic, by injection molding were exactly the same as that of neat LDPE while for the HDPE/BP compound an increase in the parameters used in injection molding was required. The corresponding mechanical properties of the compound were also examined. Tensile strength and elongation at break increased with increasing BP content at low compositions and started to decrease at high BP content for the LDPE/BP compound. However, the tensile strength and strain of the LDPE/BP compound were generally better than the neat LDPE. Therefore, not only does the presence of $\mathrm{BP}$ in the compound provide sustainable characteristics, but it also improves the mechanical properties. On the other hand, the tensile strength generally decreased for both HDPE/BP with flexible and rigid crosslinkers while the elongation at break increased. These results comply with the properties of pure LDPE and HDPE. Apart from the changing ratios of $\mathrm{BP}$ to LDPE or HDPE, the processing temperature was also considered to have an influence on the mechanical properties of the compound. By acting as a guideline, this study aids any intention on processing these in-house produced polymers via injection molding. Further research should be done in this area by decreasing the processing conditions to reduce the energy consumption.

\section{Conflict of Interests}

The authors declare that there is no conflict of interests regarding the publication of this paper.

\section{Acknowledgments}

The authors would like to thank the Malaysian Government, University Tun Hussein Onn Malaysia (UTHM), Johor, and Malaysian Technical University Centre of Excellence (MTUN $\mathrm{CoE}$ ) for supporting this research study under research Grant 
HDPE/BP
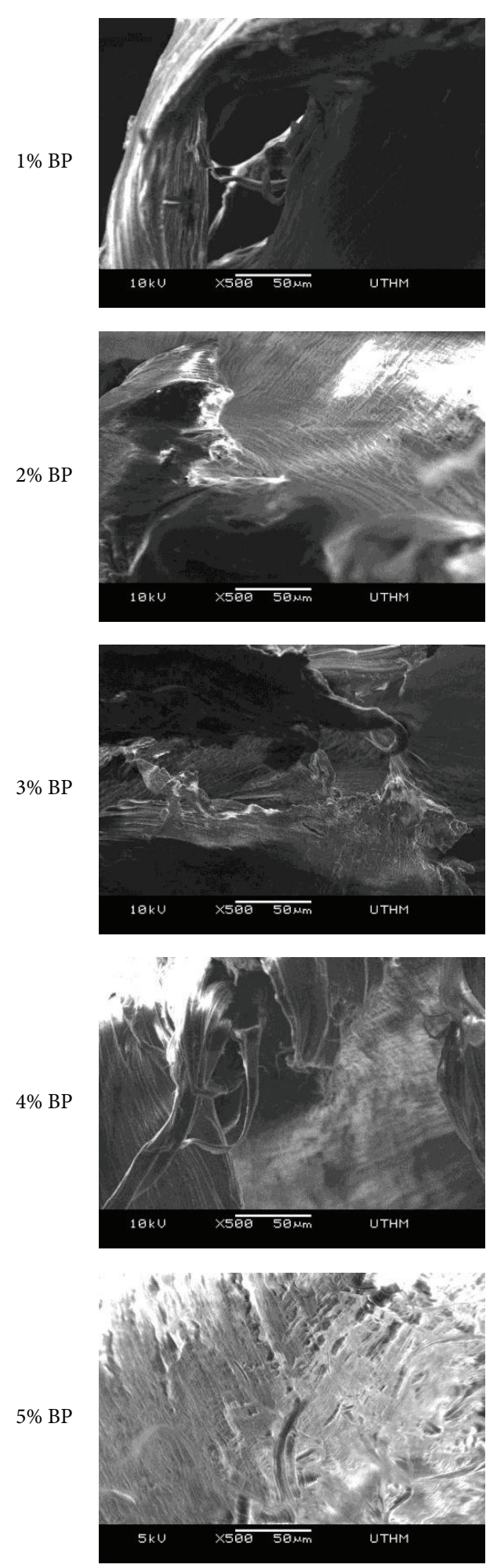

FIGURE 9: SEM images for all HDPE/BP specimens at 500x magnifications.
Rigid crosslinker

Vot C014 and Exploratory Research Grant Scheme (ERGS), E018. Not to forget, the authors express deep gratitude to the University of Auckland, New Zealand, for the research internship opportunity.

\section{References}

[1] B. John, K. T. Varughese, Z. Oommen, P. Pötschke, and S. Thomas, "Dynamic mechanical behavior of high-density polyethylene/ethylene vinyl acetate copolymer blends: the effects of the blend ratio, reactive compatibilization, and dynamic vulcanization," Journal of Applied Polymer Science, vol. 87, no. 13, pp. 2083-2099, 2003.

[2] M. Munaro and L. Akcelrud, "Polyethylene blends: a correlation study between morphology and environmental resistance," Polymer Degradation and Stability, vol. 93, no. 1, pp. 43-49, 2008.

[3] S. V. Canevarolo Jr., Ciência dos Polímeros, Editora Artliber Ltda, São Paulo, Brazil, 2006.

[4] J. Minick, A. Moet, and E. Baer, "Morphology of HDPE/LDPE blends with different thermal histories," Polymer, vol. 36, no. 10, pp. 1923-1932, 1995.

[5] J. H. Khan and N. Ahmed, "Photo-oxydative degradation of recycled, reprocessed HDPE: changes in chemical, thermal and mechanical properties," Bulgarian Journal of Physics, vol. 30, pp. 158-169, 2003.

[6] A. Z. M. Rus, "Polymer from renewable materials," Science Polymer, vol. 93, pp. 1-16, 2010.

[7] A. Z. Mohd-Rus, T. J. Kemp, and A. J. Clark, "Degradation studies of polyurethanes based on vegetable oils. Part 2. Thermal degradation and materials properties," Progress in Reaction Kinetics and Mechanism, vol. 34, no. 1, pp. 1-41, 2009.

[8] A. Min Min, T. G. Chuah, and T. R. Chantara, "Thermal and dynamic mechanical analysis of polyethylene modified with crude palm oil," Materials \& Design, vol. 29, no. 5, pp. 992-999, 2008.

[9] European-Bioplastic, Material Innovations-Biobased Low-Density Polyethylene, 2014, http://en.european-bioplastics.org/.

[10] Y. Yildiz, N. Kizilcan, and N. Uyanik, "Effects of acetophenoneformaldehyde resin on the degradation of high-density polyethylene by UV-irradiation," Pigment and Resin Technology, vol. 35, no. 5, pp. 247-251, 2006.

[11] S. Ramarad, Preparation and properties of kenaf fibre filled (plasticized polylactic asid) composites [M.S. thesis], Universiti Sains Malaysia, Penang, Malaysia, 2008.

[12] M. Ito and K. Nagai, "Degradation issues of polymer materials used in railway field," Polymer Degradation and Stability, vol. 93, no. 10, pp. 1723-1735, 2008.

[13] A. T. Bozdana and Ö. Eyercioğlu, "Development of an expert system for the determination of injection moulding parameters of thermoplastic materials: EX-PIMM," Journal of Materials Processing Technology, vol. 128, no. 1-3, pp. 113-122, 2002.

[14] S.-Y. Han, J.-K. Kwag, C.-J. Kim, T.-W. Park, and Y.-D. Jeong, "A new process of gas-assisted injection molding for faster cooling," Journal of Materials Processing Technology, vol. 155156, no. 1-3, pp. 1201-1206, 2004.

[15] S. R. Mohid, A. Z. M. Rus, and N. H. Harun, "Influence of bio polymer composites as heat absorption coating," Applied Mechanics and Materials, vol. 315, pp. 404-407, 2013.

[16] D. R. Mulinari, H. J. C. Voorwald, M. O. H. Cioffi, M. L. C. P. da Silva, T. G. da Cruz, and C. Saron, "Sugarcane bagasse
cellulose/HDPE composites obtained by extrusion," Composites Science and Technology, vol. 69, no. 2, pp. 214-219, 2009.

[17] J. M. Cervantes-Uc, J. V. Cauich-Rodríguez, H. Vázquez-Torres, and A. Licea-Claveríe, "TGA/FTIR study on thermal degradation of polymethacrylates containing carboxylic groups," Polymer Degradation and Stability, vol. 91, no. 12, pp. 3312-3321, 2006.

[18] S. S. Idris, N. A. Rahman, K. Ismail, A. B. Alias, Z. A. Rashid, and M. J. Aris, "Investigation on thermochemical behaviour of low rank Malaysian coal, oil palm sustainable mass and their blends during pyrolysis via thermogravimetric analysis (TGA)," Sustainableresource Technology, vol. 101, pp. 4584-4592, 2010.

[19] M. Ardanuy, M. Antunes, and J. I. Velasco, "Vegetable fibres from agricultural residues as thermo-mechanical reinforcement in recycled polypropylene-based green foams," Waste Management, vol. 32, no. 2, pp. 256-263, 2012.

[20] S. Ibrahim and M. R. Johan, "Thermolysis and conductivity studies of poly(ethylene oxide) (PEO) based polymer electrolytes doped with carbon nanotube," International Journal of Electrochemical Science, vol. 7, no. 3, pp. 2596-2615, 2012.

[21] S. Gopalakrishnan, N. T. Nevaditha, and C. V. Mythili, "Synthesis and characterization of bifunctional monomers for high performance polymers from renewable resource," International Journal of ChemTech Research, vol. 4, no. 1, pp. 48-54, 2012.

[22] P. S. Souza, E. F. Rodrigues, J. M. C. Prêta, S. A. S. Goulart, and D. R. Mulinari, "Mechanical properties of HDPE/textile fibers composites," Procedia Engineering, vol. 10, pp. 2040-2045, 2011.

[23] X. Zhao, R. K. Y. Li, and S.-L. Bai, "Mechanical properties of sisal fiber reinforced high density polyethylene composites: effect of fiber content, interfacial compatibilization, and manufacturing process," Composites Part A: Applied Science and Manufacturing, vol. 65, pp. 169-174, 2014.

[24] A. G. Supri, H. Salmah, and K. Hazwan, "Low density polyethylene-nanoclay composites: the effect of poly (acrylic acid) on mechanical properties, XRD, morphology properties and water absorption," Malaysian Polymer Journal, vol. 3, no. 2, pp. 39-53, 2008. 

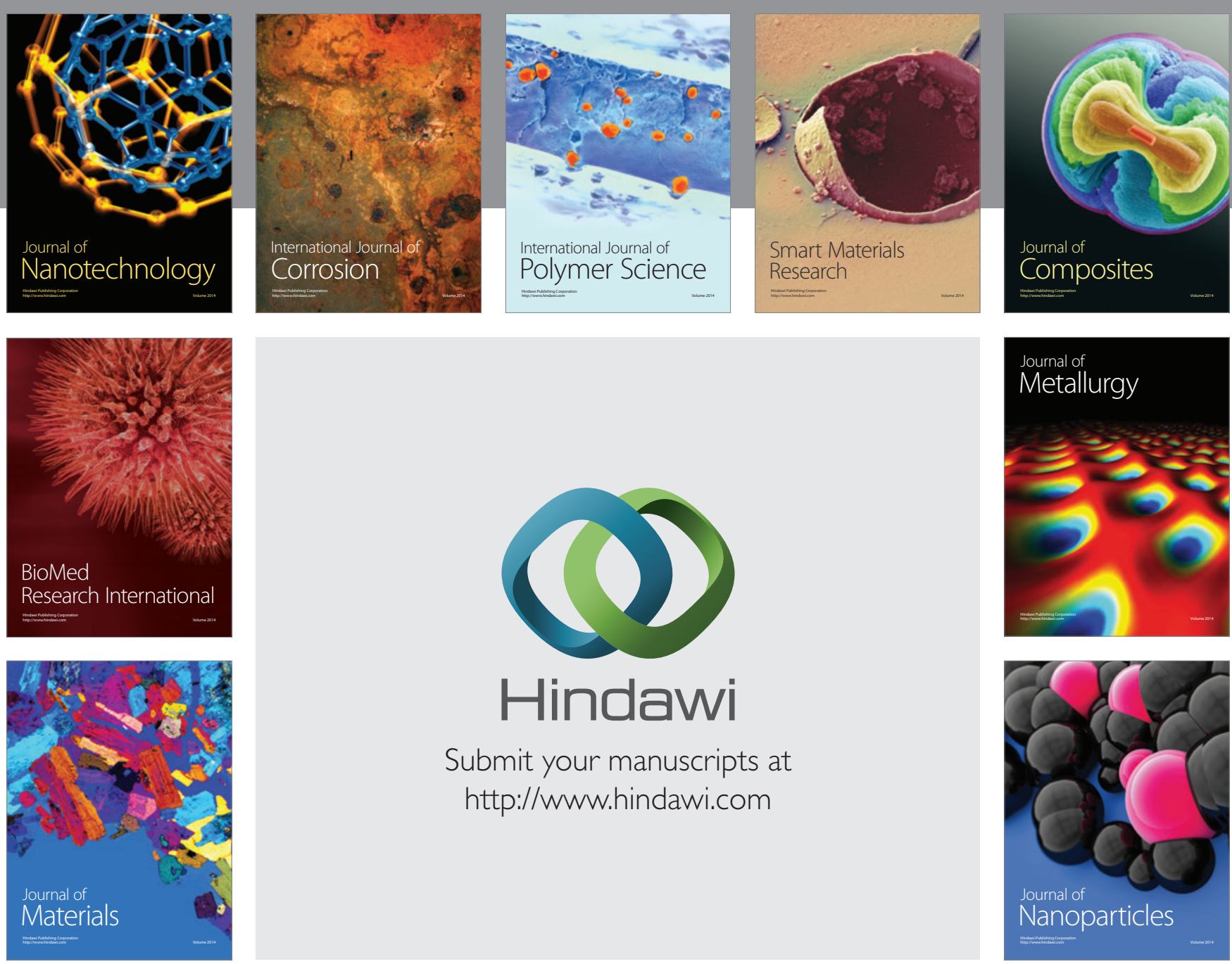

Submit your manuscripts at http://www.hindawi.com
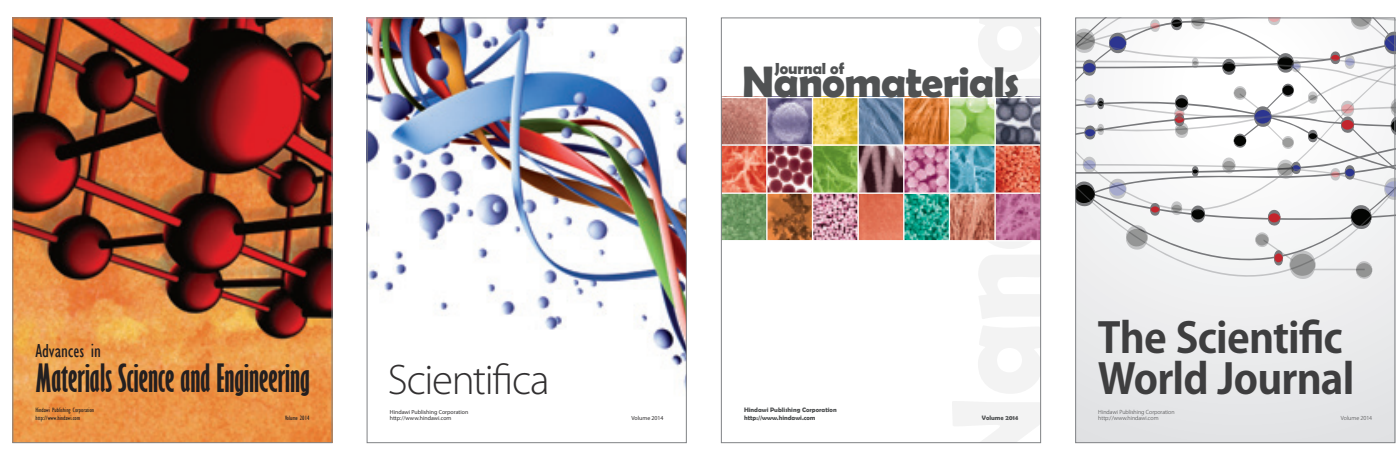

\section{The Scientific World Journal}
